

\title{
Additives as a major source of radiolytic organic byproducts of polyvinyl chloride (PVC)
}

\author{
Mathilde Chantreux, Denise Ricard, Laurence Asia, Stéphanie Rossignol, \\ Pascal Wong-Wah-Chung
}

\section{To cite this version:}

Mathilde Chantreux, Denise Ricard, Laurence Asia, Stéphanie Rossignol, Pascal Wong-Wah-Chung. Additives as a major source of radiolytic organic byproducts of polyvinyl chloride (PVC). Radiation Physics and Chemistry, 2021, 188, pp.109671. 10.1016/j.radphyschem.2021.109671 . hal-03576676

\section{HAL Id: hal-03576676 https://hal.science/hal-03576676}

Submitted on 16 Feb 2022

HAL is a multi-disciplinary open access archive for the deposit and dissemination of scientific research documents, whether they are published or not. The documents may come from teaching and research institutions in France or abroad, or from public or private research centers.
L'archive ouverte pluridisciplinaire HAL, est destinée au dépôt et à la diffusion de documents scientifiques de niveau recherche, publiés ou non, émanant des établissements d'enseignement et de recherche français ou étrangers, des laboratoires publics ou privés. 


\title{
Additives as a major source of radiolytic organic byproducts of polyvinyl chloride (PVC)
}

Mathilde Chantreux ${ }^{1,2}$, Denise Ricard ${ }^{2}$, Laurence Asia ${ }^{1}$, Stéphanie Rossignol ${ }^{1}$ and Pascal Wong-WahChung $^{1 *}$

1 Aix Marseille Univ, CNRS, LCE, Marseille, France

2 ANDRA, 1/7 rue Jean Monnet, Châtenay-Malabry, France

* Corresponding authors:

Pascal Wong-Wah-Chung: Université Aix-Marseille -Laboratoire de Chimie de l'Environnement UMR CNRS 7376-Europôle de l'Arbois -Bât Villemin - BP80 - 13545 Aix-en-Provence Cedex 4, France

pascal.wong-wah-chung@univ-amu.fr $\quad$ Tel.; +33442908402

\begin{abstract}
Polyvinyl chloride (PVC), one of the most polymeric materials present in the radioactive waste, is exposed to radiooxidation process during disposal and generates many byproducts. Commercial PVC materials usually contain many additives to provide desired properties and to improve their stability during shaping and lifetime. The additives generally delay PVC radiolysis limiting the formation of some PVC transformation compounds, but they can indubitably generate byproducts as well. Hence, the present work investigates the role of the additives in formulated PVC on the nature and kinetics of the released radiolytic compounds. Four PVC samples, one resin, two PVC formulated on purpose and one commercial PVC containing different additives (at least di-isononyl phthalate (DINP) as plasticizer) were exposed to $\gamma$ irradiation. Analyses by thermal desorption-GC-MS and solvent extraction coupled with GC-MS were undertaken to identify radio oxidative products. Higher amounts of volatile and non-volatile organic compounds were detected in formulated PVC compared to PVC resin. Some are products coming from the degradation of the polymer chain while the others result mainly from the radiolytic degradation of DINP plasticizer. Commercial PVC containing the widest range of additives (among other lubricants) produced additional byproducts coming from their degradation. Based on the identification and evolution of the radio oxidized products, mechanistic pathways involved in the radiolytic degradation of formulated PVC are proposed.
\end{abstract}

Keywords: PVC, radiolysis, degradation products, additives, DINP plasticizer 


\section{Introduction}

Radioactive waste is generated by the use of radioactive materials in industry, research and medicine, as well as in nuclear power plant. The management and disposal of such waste is, therefore, a very important issue. In France, the estimated volume for the low intermediatelevel long-lived radioactive waste is around 43,000 $\mathrm{m}^{3}$ according to the inventory at end 2018 (Andra, 2020). This category includes, among others, organic materials such as chlorinated and fluorinated polymers, polyolefins, polyurethanes and polyacrylates. Chlorinated polymers, like polyvinyl chloride (PVC), are one of the most used. This material is primarily present in the waste as bags or glove box sleeves, but also as thicker pieces such as filter housings.

Under disposal conditions, PVC can be exposed to different processes of degradation and in particular to radiooxidation process that implies the concomitant action of gamma radiation and oxygen (Colombani et al., 2007; Decker, 1976; Hegazy et al., 1981; Miller, 1959; Salovey and Luongo, 1970; Zahran et al., 1985). PVC radiooxidation leads to structural changes in the polymer such as chain scission or cross-linking (Miller, 1959) and the main identified reaction byproducts are $\mathrm{HCl}, \mathrm{H}_{2}, \mathrm{CO}_{2}$ and $\mathrm{CO}$ gases and some carbonyl compounds and carboxylic acids (Colombani et al., 2007; Decker, 1976).

Most of the authors describe the radiooxidation mechanisms of the PVC matrix and less attention has been paid to the effect of the additives (plasticizers, heat stabilizers, lubricants, flame retardants and fillers) on the generated byproducts, despite the fact that these constituents are in very large amount in commercial PVC (until 80\% in mass) (Kresta, 1984; Schiller, 2015; Štěpek and Daoust, 2012). Generally, the role of the additives on the radiochemical yields of $\mathrm{HCl}$ and $\mathrm{H}_{2}$ gas has been explored without real consensus. Some studies on formulated and/or industrial PVC radiolysis have shown that heat stabilizers associated with phthalate plasticizers or calcium fillers delay or inhibit the formation of radiolysis gases (Hegazy et al., 1981 ; Lerke and Szymański, 1983; Colombani, 2007). However, recent work demonstrates that the presence of DINP plasticizer in PVC formulation increases the radiochemical yield of $\mathrm{H}_{2}$ production (Boughattas, 2014). In addition to the studies on $\mathrm{HCl}$ and $\mathrm{H}_{2}$, only one work on plasticized PVC evidenced the formation of carbonyl compounds (Krylova et al., 1979) without any detail on the byproducts structure, kinetics or formation mechanism.

This work proposes an extensive study of the organic degradation products resulting from the radiooxidation of formulated PVC using powerful analytical techniques: thermal desorption coupled with GC-MS (TD-GC-MS) and liquid extraction with solvents or solubilizationprecipitation approach coupled with GC-MS. The objectives are (i) to identify the byproducts 
and set their evolution with irradiation dose, (ii) to discriminate their source (PVC polymer or additives) and (iii) to propose mechanistic pathways leading to their formation in formulated PVC.

\section{Experimental}

\subsection{Material}

Several types of PVC were used to study the influence of the formulation on the radiooxidation process. First, an additive-free PVC, the resin (R) (grade K70) Lacovyl PB1302 produced by KemOne society (Saint-Auban, France) by micro suspension polymerization process. The resin in powder form was used as provided.

Two different formulations were produced from this pure resin: formulation 1 (F1) containing $43 \mathrm{phr}$ of diisononyl phthalate (DINP, A2S, 99\%) and formulation 2 (F2) containing $41 \mathrm{phr}$ of the latter and $2 \mathrm{phr}$ of a heat stabilizer (Baerostab CT9169 Ca/Zn). Films of about 215 $\mu \mathrm{m}$ thickness were shaped by coating $\left(30 \mathrm{~s}\right.$ at $200{ }^{\circ} \mathrm{C}$ ) from these two formulated PVC.

The third film studied was a commercial PVC (P), prepared by calendaring and provided by Plastunion society (Bondy, France) and referred as 1338 TA. It was made from a resin mixture (grades K70 and K75) and contained 49 phr of DINP, $2.2 \mathrm{phr}$ of heat stabilizer (metals organic derivatives $(\mathrm{Ca} / \mathrm{Zn})$ ) and $3.6 \mathrm{phr}$ of other additives (stearic acid, calcium stearate, talc). The Plastunion PVC (P) film was about $175 \mu \mathrm{m}$ thickness.

\subsection{Irradiations}

$\gamma$-irradiations were carried out for films of F1, F2 and P $(14 \times 30 \mathrm{~cm})$ and for the resin powder R, each PVC being packaged in glass jars. Above each jar, a perforated glass plate was placed to ensure a good oxygen circulation during the irradiation and to protect samples from atmospheric residues. Static irradiation is provided by a ${ }^{60} \mathrm{Co}$ source placed in front of the samples. The rate was fixed at approximately $1 \mathrm{kGy} \cdot \mathrm{h}^{-1}$ and the target integrated doses were around $0.5,1$, and $2 \mathrm{MGy}$. All gamma radiations exposure conditions are gathered in Table $1 \mathrm{~S}$ in the Supporting Information (SI).

\subsection{Methods}

\section{Extraction protocols}


A dissolution/precipitation technique was developed, dissolving $100 \mathrm{mg}$ of PVC in $3 \mathrm{~mL}$ of tetrahydrofuran (Sigma Aldrich, inhibitor-free, HPLC > $99.9 \%$ ). Then, $10 \mathrm{~mL}$ of hexane (Sigma Aldrich, $94 \%$ HPLC grade) and methanol (Sigma Aldrich, $99.9 \%$ HPLC grade), $(50 / 50, \mathrm{v} / \mathrm{v})$ were added to precipitate the polymer. After centrifugation $\left(5500 \mathrm{rpm}\right.$ at $20{ }^{\circ} \mathrm{C}$ during $7 \mathrm{~min}$ ), the extract is recovered and injected in GC-MS after dilution in hexane. The dilution factor (between 500 and 1) was adapted according to the target molecules to be identified. Extracts were injected after filtration on a $0.2 \mu \mathrm{m}$ PTFE filter (Chromacol4-SF-02, ThermoScientific).

Solid-liquid extraction (SLE) was also undertaken with $100 \mathrm{mg}$ of PVC sample and $5 \mathrm{~mL}$ of methanol, stirring for 24 hours (Bioblock Scientific, $150 \mathrm{rpm}$ ). Successive extractions over 48 hours allow the validation of the method as no other compounds were detected. An additional SLE protocol with dichloromethane (DCM, GC-MS Suprasolv, Merck) was used to measure DINP concentration in PVC samples (10 mg into $10 \mathrm{~mL})$.

\section{Gas chromatography-Mass spectrometry (GC-MS)}

GC-MS analyses were achieved on the one hand to follow DINP degradationduring irradiation and on the other hand to identify PVC radiooxidation products. They were performed with an Auto system XL connected to a Turbomass mass spectrometer from Perkin Elmer. Two different columns of $30 \mathrm{~m} \times 0.25 \mathrm{~mm} \times 0.25 \mu \mathrm{m}$ were used: an Elite-5MS (Perkin Elmer) to quantify DINP and a SPB-50 (Supelco) and a Supelcowax (Sigma Aldrich) for the degradation products. A common heating program was applied: $50^{\circ} \mathrm{C}(1 \mathrm{~min}), 20^{\circ} \mathrm{C} \cdot \mathrm{min}^{-1}$ (1 to $\left.16 \mathrm{~min}\right)$, and $10^{\circ} \mathrm{C} \cdot \mathrm{min}^{-1}$ until a final temperature maintained for $10 \mathrm{~min}$ and adjusted as a function of the column $\left(300^{\circ} \mathrm{C}\right.$ for the Elite-5MS and $280^{\circ} \mathrm{C}$ for the others). The carrier gas was helium at a flow rate of $1 \mathrm{~mL} \cdot \mathrm{min}^{-1}$ and $1 \mu \mathrm{L}$ of the solution was injected at $290^{\circ} \mathrm{C}$. The transfer line temperature was fixed at $270^{\circ} \mathrm{C}$, the mass spectrometer was equipped with an electron impact source at $230^{\circ} \mathrm{C}$ and the analyzer was a simple quadrupole.

Quantification of DINP was carried out in Single Ion Monitoring (SIM) acquisition mode, using $m / z, 293$ for DINP and $m / z, 149$ for the internal standard di-butyl phthalate (DBP, A2S, 99 $\%)$. The recovery and precision were assessed by replicate analysis $(\mathrm{n}=3)$ for two successive extractions. Total recoveries calculated for the non-irradiated samples vary between 94.0 and $100.9 \%$ (RSD: $2.08 \%-8.95 \%$ ).

For the detection of the radiooxidation products, MS detector operated in scan mode over a mass-range of 50-600 amu and the chemical attribution was based on the correlation with the NIST library with a correlation coefficient upper than $70 \%$, validating hypotheses with the 
literature. Extinctions of the filament were applied to avoid the analysis of molecules in high concentration and to allow the detection of traces.

Thermo-desorption coupled to gas chromatography-mass spectrometry (TD-GC-MS)

TD-GC-MS analyses allowed the identification and semi-quantification of Volatile Organic Compounds (VOCs) present in the polymer matrix. Analyses were made with an ATD 350 coupled to a Clarus 600 gas chromatographer and a Clarus $600 \mathrm{~T}$ mass spectrometer from Perkin Elmer. The transfer line between ATD and GC was fixed at $280^{\circ} \mathrm{C}$. The column was a Perkin Elmer Elite-5MS $(30 \mathrm{~m} \times 0.25 \mathrm{~mm} \times 1 \mu \mathrm{m})$. The temperature program was $40^{\circ} \mathrm{C}(2$ $\min ), 3^{\circ} \mathrm{C} \cdot \mathrm{min}^{-1}\left(92^{\circ} \mathrm{C}\right), 5^{\circ} \mathrm{C} \cdot \mathrm{min}^{-1}\left(160^{\circ} \mathrm{C}\right), 10^{\circ} \mathrm{C} \cdot \mathrm{min}^{-1}\left(280^{\circ} \mathrm{C}, 10 \mathrm{~min}\right)$. The transfer line temperature was fixed at $280^{\circ} \mathrm{C}$, the mass spectrometer was equipped with an electron impact source maintained at $250^{\circ} \mathrm{C}$ and the analyzer was a simple quadrupole. Approximately $30 \mathrm{mg}$ (+/- $2 \mathrm{mg}$ ) of PVC samples were introduced in conditioned stainless-steel tubes (Perkin Elmer, $\mathrm{CO} 3482$ ) and heated at $90^{\circ} \mathrm{C}$ during 30 min under helium flux. The cold trap of the ATD was maintained at $-30^{\circ} \mathrm{C}$ during sample desorption and was then heated at $300^{\circ} \mathrm{C}$ (rate of $99^{\circ} \mathrm{C} . \mathrm{s}^{-1}$ ) to inject the analytes. Scan mode from 29 to 520 amu enabled the identification. For every sample, a total of seven cycles of TD-GC-MS analysis was applied.

A semi-quantification of VOCs contained in the PVC samples was carried out in toluene equivalent and achieved using Tenax ${ }^{\circledR}$ TA tubes spiked with toluene (Sigma Aldrich, $99.8 \%$ ) for the calibration. According to the calibration curve (Figure 1S), the total VOCs quantification was performed up to $\mathrm{C} 20$. Eicosane $\left(\mathrm{C}_{20} \mathrm{H}_{42}\right)$, used as a reference, was injected and has a retention time of $43.5 \mathrm{~min}$. All compounds within 2.93 and $43.5 \mathrm{~min}$ (excluding $\mathrm{HCl}$ and $\mathrm{CO}_{2}$ ) will therefore be considered for the calculation.

The total VOC concentration $\left(\mathrm{C}_{\mathrm{VOC}}(\mathrm{nC} 20)\right.$ in $\left.\mu \mathrm{g} \cdot \mathrm{g}^{-1}\right)$ was calculated as follow:

$$
\operatorname{Cvoc}(\mathrm{nC} 20)=\sum_{\leq \mathrm{nC} 20} \mathrm{C}_{\text {compound }}
$$

With: $\quad \mathrm{C}_{\text {compound }}=\mathrm{S}_{\text {compound }} / K_{\text {(toluene) }} \times \mathrm{M}_{\text {sample }}$

With $S_{\text {compound }}$ the peak area of the compound, $K_{\text {(toluene) }}$ the slope of the calibration curve $\left(\mu \mathrm{g}^{-1}\right)$, $\mathrm{M}_{\text {sample }}$ the PVC sample mass $(\mathrm{g})$ and $\mathrm{C}_{\text {compound }}$ the equivalent toluene concentration $\left(\mu \mathrm{g} \cdot \mathrm{g}^{-1}\right)$. The $\mathrm{C}_{\mathrm{voc}}(\mathrm{nC} 20)$ values presented afterwards correspond to the COVs formed upon radiooxidation only: the VOCs signal obtained for each non-exposed PVC sample were 
subtracted to the VOCs signals obtained for each corresponding $\gamma$-exposed PVC sample. The repeatability of the analytical method was assessed by two successive injections of toluene standard (RSD: $2.05 \%$ ). For PVC analysis, reproducibility was also considered given the heterogeneity of the samples, to consider errors on the toluene equivalent concentrations. 


\section{Results and discussion}

\subsection{Study of the volatile radiooxidation products by TD-GC-MS}

The analysis of the PVC resin, the two on purpose formulated PVC and the commercial Plastunion PVC irradiated samples by TD-GC-MS allowed to detect many radiooxidation products (at least 30 predominant) and thermooxidation ones as previously reported (Boughattas et al., 2016). The latter were identified from the fourth to the seventh cycle of TDGC-MS analysis assuming that the total extraction of the radiooxidation products was reached after three cycles as confirmed by their calculated desorbed fractions using equation $1 \mathrm{~S}$ and gathered in Table $2 \mathrm{~S}$ in Supplementary information. Some of the observed radiooxidative products were common to all PVC samples and others were specific to formulated PVC (Figure $2 \mathrm{~S}$ ). Common VOCs can be attributed to the radiooxidation of the polymer matrix while the additional ones certainly involve other pathways.

VOCs' concentrations were calculated by subtracting the contribution of the thermooxidation products to the total area for each first three TD-GC-MS cycles and total VOCs were determined by adding corrected VOCs' concentrations of the three successive analysis. Thus, the evolution of the total VOC concentrations has been determined as a function of the irradiation dose (Figure 3S). An increase of the concentration is systematically observed with the $\gamma$-dose and this concentration remains lower in the resin than in the formulated PVC especially for the lowest irradiation doses ( 0.5 and $1 \mathrm{MGy})$. This can be explained by the fact that the volatile compounds are generated from the degradation of the polymer matrix but also from the degradation of the additives.

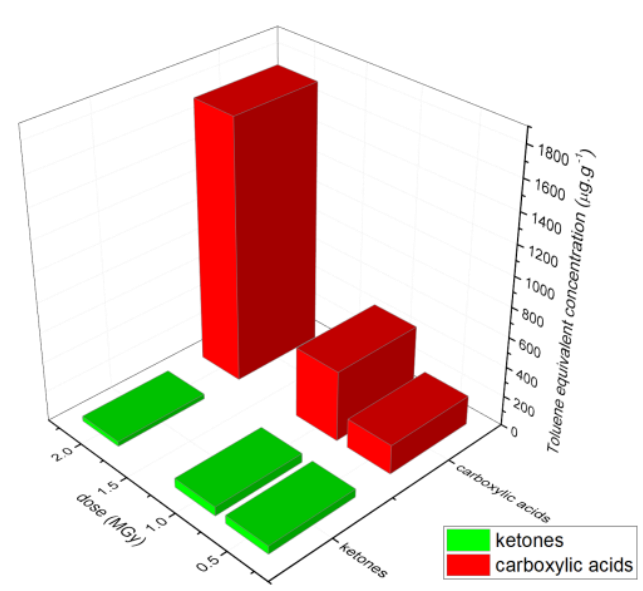

Resin



Formulation 1 


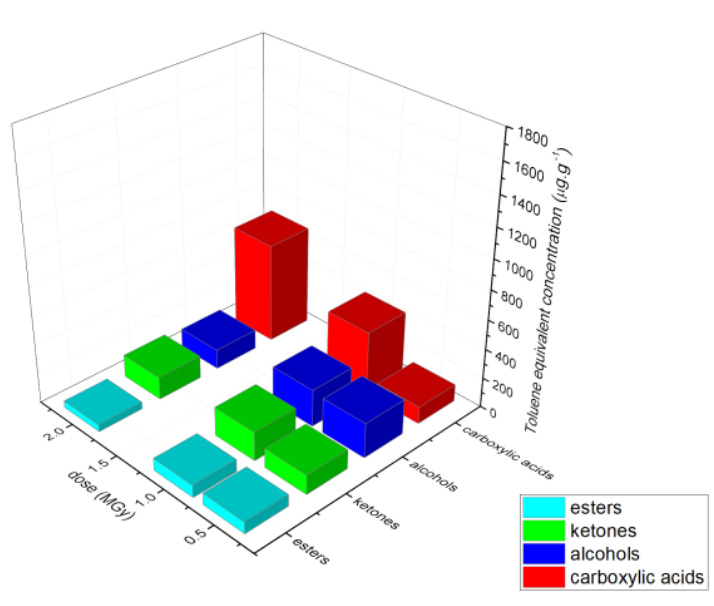

Formulation 2

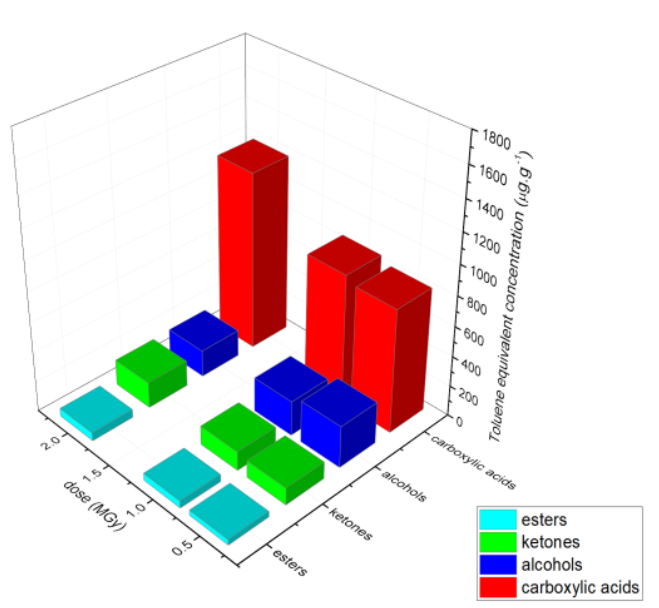

Plastunion

Figure 1: Evolution of main VOCs concentration as a function of the $\gamma$-dose expressed in toluene equivalent concentration $\left(\mu \mathrm{g} \cdot \mathrm{g}^{-1}\right)$ determined by TD-GC-MS.

As presented on Figure 1, the radiooxidation of the PVC resin leads to the formation of two main classes of VOCs: carboxylic acids, and ketones in much smaller quantity. Formulated PVCs generate identical but also additional volatile compounds such as esters, ketones and alcohols probably attributed to the presence of additives, mostly DINP, the common component in all the three formulations.

To have better insight in these behaviors, the further identification of these volatile degradation products was carried out. Only the most abundant ones (with a concentration higher than 100 $\mu \mathrm{g} \cdot \mathrm{g}^{-1}$ in toluene equivalent) are presented in Table 1. The formation of some of them are presented in Figure 2 and in SI by summing up the areas obtained from the successive cycles. The results are presented in toluene equivalent concentration, except for formic acid evolution, that was established from the area of the extracted chromatograms at $m / z=46$, its peak being hidden by $\mathrm{HCl}$ in full scan mode. 
Table 1: Molecule name, retention time ( $\mathrm{t}_{\mathrm{r}}$ ), proposed structure, matching coefficient (MC) with NIST library of the radiooxidated PVC samples identified by TD-GC-MS and their presence (x) in the samples at $2 \mathrm{MGy}$.

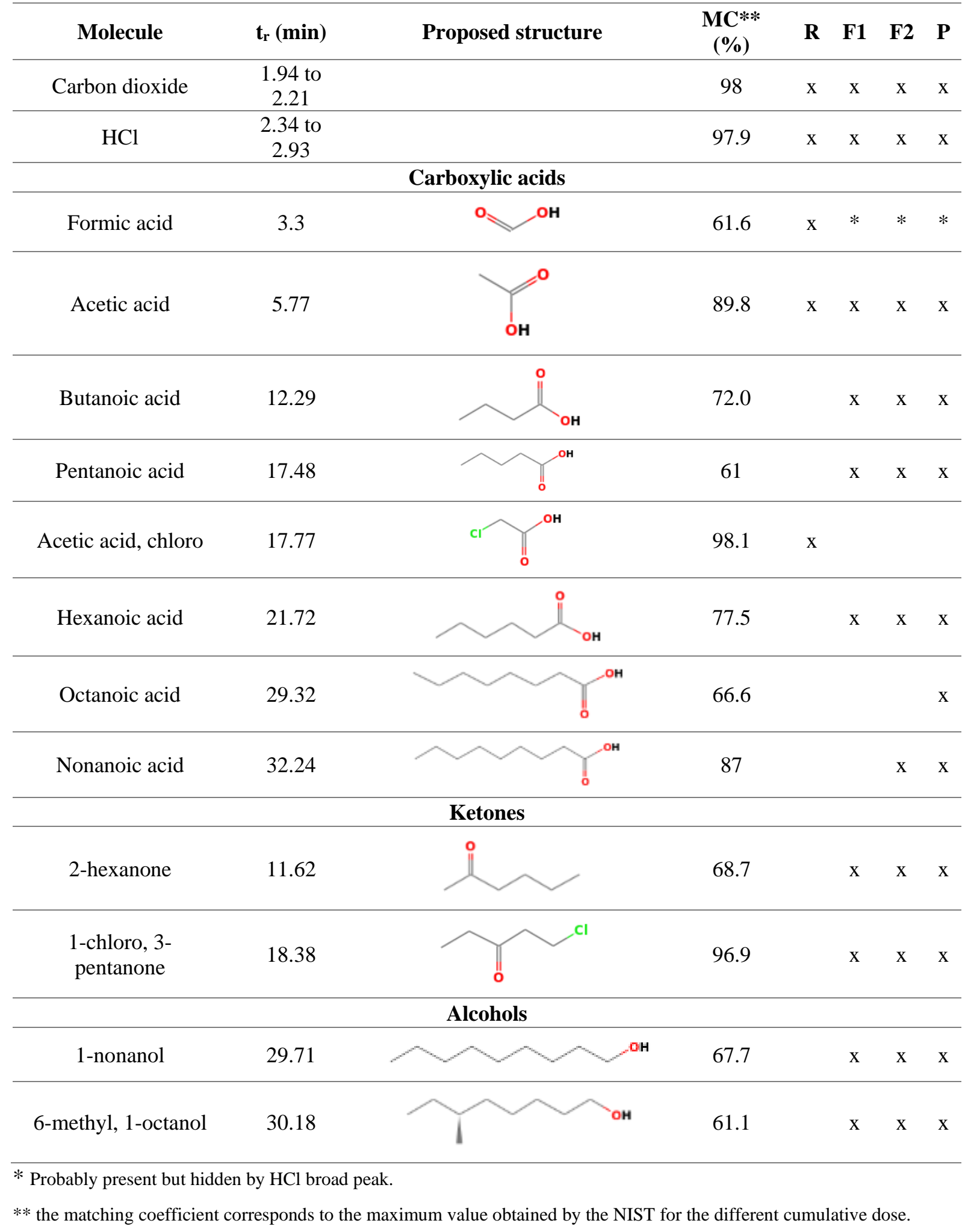






Figure 2 : Concentration evolution of acetic acid and carboxylic acids (C4 to C9) by TD-GCMS as a function of the $\gamma$-dose in all formulated PVC samples: resin (black), F1 (red), F2 (blue) and $\mathrm{P}$ (green). Error bars have been calculated considering the reproducibility of heterogeneous samples analysis. 
Five volatile byproducts were detected for the resin $(\mathrm{R})$ and nine additional ones in the formulated PVC samples (F1, F2 and P). Remaining $\mathrm{CO}_{2}$ and $\mathrm{HCl}$ into $\mathrm{PVC}$ matrix have been detected in large amounts in all PVC samples. Their concentrations increase with the irradiation dose as presented in Figure 4S (Miller. 1959; Salovey and Luongo. 1970; Zahran et al. 1985; Boughattas et al.. 2016) and are affected by the formulation, plasticizer stabilizing the radiolytic abstraction of $\mathrm{HCl}$ from PVC (Hutzler et al., 2000; Krylova et al., 1979). Acetic and formic acid are also well-known byproducts generated from the PVC matrix radiooxidation (Colombani et al., 2007). However, it appears that the formic and acetic acid formation is delayed in the formulated PVC, in a more remarkable way for acetic acid in the heat stabilized and plasticized formulation (F2) and in the commercial one (Plastunion). This strengthens the role of these additives as previously demonstrated by Hegazy et al. (1981) for the radiolysis gases. Chloro-acetic acid is mainly detected in the PVC resin, and it is proposed that chloroacetic acid results either from the recombination reaction of the acetic acid radical $\left({ }^{\circ} \mathrm{CH}_{2} \mathrm{COOH}\right)$ with chlorine radical $\left(\mathrm{Cl}^{\bullet}\right)$ or by the oxidation of chloro-acetaldehyde (detected at trace level, not shown in Table 1). Colombani et al. (2007) also proposes that it can come from the hydrolysis of the corresponding acid chloride.

Moreover, the additives appear to generate a wide range of additional volatile byproducts, corresponding to the ones exclusively detected in the formulated PVC samples. These are mainly carboxylic acids with longer alkyl chain and, in a lesser extent, ketones and alcohols (Table 1). These additional volatiles products represent about $70 \%$ of the total VOC concentration on average for the three formulated samples between 0.5 and $2 \mathrm{MGy}$.

Concentration evolution of the four main ones are presented in Figure 2. For butanoic acid, the results show that its formation similarly occurs for all formulations until a dose of $1 \mathrm{MGy}$, and that beyond this value, the behavior depends on the PVC sample: butanoic acid concentration is comparable for F1 et F2 samples and increases for Plastunion sample. This means that in the early stages of the $\gamma$-exposure, the source of butanoic acid is identical in all formulations and should necessary be DINP as it is the only additive present in F1. For high exposure dose, the degradation of this acid probably becomes competitive with its formation in F1 and F2 samples and additional source (other than thermal stabilizer and DINP) probably contributes to its formation in Plastunion. For all the formulations, the curve shape suggests that butanoic acid is a secondary product. Pentanoic acid is continuously formed for the three formulations but in higher amount in Plastunion PVC sample compared to the others. This suggests that pentanoic acid can originate from DINP but also from other sources all along the exposure in Plastunion. 
For hexanoic and nonanoic acids, it can be noticed that they appear as primary products since they are formed in the early stages of the $\gamma$ exposure to reach a maximum at 0.5 or $1 \mathrm{MGy}$ and then disappear to give secondary products. The same trend was observed for the alcohols (1nonanol and 6 methyl, 1-octanol) as presented in figure $5 \mathrm{~S}$ making them primary products. However, C6 and C9 acids are formed in different amount as a function of the PVC formulation. The comparable hexanoic acid concentration for F1 and F2 samples means that it is probably produced from DINP. The low amount of nonanoic acid detected in F1 samples compared to F2 samples could be due to its favored degradation in the absence of stabilizers. Finally, the high amount of these two acids in Plastunion PVC samples can be attributed to a wider variety of potential sources, as described for butanoic and pentanoic acid.

For the two detected alcohols, comparable curves shape and concentration are observed whatever the formulation (Figure 5S) meaning that they probably originate only from the degradation of the unique common compound in the three formulation, DINP.

\subsection{Radiooxidation products identification after solvent extraction}

Extraction protocols involving two solvents (MeOH and THF) and GC-MS analyses using two columns (a polar (Supelcowax) and a semi-polar one (SBP50)) were developed to ensure the largest identification of byproducts. Different solvents were tested for the extraction because some PVC samples were insoluble in THF or their reprecipitation unfeasible beyond a dose of 2 MGy.

Most of the compounds were detected after a MeOH extraction. They are gathered in Table 2 and are mainly chlorinated and non-chlorinated esters of mono and diacid compounds from C2 to C9. It is supposed that during the methanol extraction, all carboxylic acids are certainly esterified by the solvent and thus, that the radiooxidation byproducts are the carboxylic acids and not their corresponding detected esters. The use of THF as an extractive solvent allows to detect one ester and a lactone (butyrolactone) and to validate the presence of phthalic acid.

For the resin, one can notice the presence of three dicarboxylic acids from $\mathrm{C} 2$ to $\mathrm{C} 4$ (ethanedioic, butanedioic and propanedioic acids) in significant amount. These compounds probably result from the radical recombination under $\gamma$ exposure of acetic and formic acid that have been evidenced in large amount by TD-GC-MS.

For all formulated PVC, some byproducts detected by TD-GC-MS are also evidenced herein (hexanoic and nonanoic acids and traces of nonanol and methyl-octanol not showed 
here), but various additional compounds were identified by solvent extraction coupled to GCMS. 
Table 2: Molecule name, retention time $\left(\mathrm{t}_{\mathrm{r}}\right)$, proposed structure, matching coefficient (MC) with NIST library of the methyl esterified radiooxidated PVC samples byproducts identified with GC-MS by extraction with $\mathrm{MeOH}$ and their presence (x) in the samples at 2 MGy

$\begin{array}{lcccccccc}\text { Molecule } & \text { Proposed structure } & \underset{(\%)}{M C *} & \begin{array}{c}\mathbf{t}_{\mathbf{r}} \\ (\mathrm{min})\end{array} & \begin{array}{c}\text { GC-MS } \\ \text { column }\end{array} & \mathbf{R} & \text { F1 } & \text { F2 } & \text { P }\end{array}$

\section{Esters (esterified carboxylic acids)}

\begin{tabular}{|c|c|c|c|c|c|c|c|}
\hline $\begin{array}{l}\text { Hexanoic acid methyl } \\
\text { ester }\end{array}$ & 91.3 & 5.37 & Supelcowax & & $\mathrm{x}$ & $\mathrm{x}$ & $\mathrm{x}$ \\
\hline $\begin{array}{l}\text { Ethanedioic acid, } \\
\text { dimethyl ester }\end{array}$ & 80.9 & 6.09 & Supelcowax & $\mathrm{x}$ & $\mathrm{x}$ & $\mathrm{x}$ & $\mathrm{x}$ \\
\hline $\begin{array}{l}\text { Acetic acid, chloro } \\
\text { methyl ester }\end{array}$ & 98.3 & 6.40 & Supelcowax & $\mathrm{x}$ & $\mathrm{x}$ & $\mathrm{x}$ & $\mathrm{X}$ \\
\hline $\begin{array}{l}\text { Propanoic acid, 3-chloro- } \\
\text { methyl ester }\end{array}$ & 92.5 & 7,24 & $\begin{array}{c}\text { SBP50 } \\
\text { Supelcowax }\end{array}$ & $\mathrm{x}$ & $\mathrm{X}$ & $\mathrm{x}$ & $\mathrm{X}$ \\
\hline $\begin{array}{l}\text { Acetic-acid, dichloro- } \\
\text { methyl ester }\end{array}$ & 94.6 & 7.53 & $\begin{array}{c}\text { SBP50 } \\
\text { Supelcowax }\end{array}$ & $\mathrm{x}$ & & & \\
\hline $\begin{array}{l}\text { Butanedioic acid, } \\
\text { dimethyl ester }\end{array}$ & 92.7 & 8.93 & SBP50 & $\mathrm{x}$ & $\mathrm{x}$ & $\mathrm{x}$ & $\mathrm{X}$ \\
\hline $\begin{array}{l}\text { Nonanoic acid methyl } \\
\text { ester }\end{array}$ & 73.7 & 9.08 & Supelcowax & & $\mathrm{x}$ & $\mathrm{x}$ & $\mathrm{X}$ \\
\hline $\begin{array}{l}\text { Propanedioic acid, } \\
\text { dimethyl ester }\end{array}$ & 97 & 9.34 & $\begin{array}{l}\text { Supelcowax } \\
\text { SPB50 }\end{array}$ & $\mathrm{x}$ & $\mathrm{x}$ & $\mathrm{x}$ & $\mathrm{X}$ \\
\hline $\begin{array}{l}\text { Hexanedioic acid } \\
\text { dimethyl ester }\end{array}$ & 73.4 & 12.95 & Supelcowax & & & & $\mathrm{x}$ \\
\hline $\begin{array}{l}\text { Heptanedioic acid } \\
\text { dimethyl ester }\end{array}$ & 76.8 & 14.06 & Supelcowax & & & & $\mathrm{X}$ \\
\hline $\begin{array}{l}\text { Phthalic acid, dimethyl } \\
\text { ester }\end{array}$ & 78 & 14.50 & $\begin{array}{c}\text { SPB50 } \\
\text { Supelcowax }\end{array}$ & & $\mathrm{X}$ & $\mathrm{x}$ & $\mathrm{x}$ \\
\hline $\begin{array}{l}\text { Pentanedioic acid, 2- } \\
\text { chloro, dimethyl ester }\end{array}$ & 74.1 & 14.54 & Supelcowax & $\mathrm{x}$ & & & \\
\hline $\begin{array}{l}\text { Octanedioic acid } \\
\text { dimethyl ester }\end{array}$ & 82.7 & 15.15 & Supelcowax & & & & $\mathrm{x}$ \\
\hline $\begin{array}{l}\text { Nonanedioic acid, } \\
\text { dimethyl ester }\end{array}$ & 90 & 16.19 & $\begin{array}{c}\text { SBP50 } \\
\text { Supelcowax }\end{array}$ & & & & $\mathrm{X}$ \\
\hline Methyl nonyl phthalate & 51.2 & 17.52 & Supelcowax & & $\mathrm{x}$ & $\mathrm{x}$ & $\mathrm{x}$ \\
\hline
\end{tabular}

\footnotetext{
* the matching coefficient corresponds to the maximum value obtained by the NIST for the different cumulative dose.
} 
Among others, one can notice the formation in high amount of phthalic acid, which is presented in Figure 3. Phthalic acid is generated in the early stages of $\gamma$ exposure and reaches a pseudoplateau after a dose of $1 \mathrm{MGy}$. It is certainly originated from DINP as it is formed in the three formulations in similar quantities. DINP transformation was established and is also presented in Figure 3. The degradation of the phthalate plasticizer increases with the $\gamma$ dose as already described in the literature for DINP (Krylova et al., 1979; Mendizabal et al., 1996) and diethylhexylphthalate (Ito et al., 2009). DINP concentration decrease is correlated with the increase of phthalic acid concentration, confirming the assumption. Beyond $1 \mathrm{MGy}$, phthalic acid degradation probably becomes competitive with formation from DINP, leading to the observed pseudo-plateau on the curves. Another hypothesis could be the grafting reactions of DINP radicals on PVC chains as described in the literature (Krylova et al. 1979; Mendizabal et al. 1996).


Figure 3: Evolution ofphthalic acid formation and degradation of DINP by GC-MS (THF and $\mathrm{MeOH}, \mathrm{SPB} 50$ ) as a function of the $\gamma$-dose in all PVC formulations (SIM, $\mathrm{m} / z=104 \mathrm{and} \mathrm{m} / \mathrm{z}$ $=293$ respectively)

In addition, many dicarboxylic acids from C6 to C8 were evidenced only in Plastunion samples. The absence of these compounds in F1 and F2 samples indicates that they are generated by other additives than DINP, i.e., heat stabilizers other than the ones present in F2 and/or by stearic acid and calcium stearate used as lubricants. This assumption of a variety of byproduct sources in Plastunion is the same that also applies for the above presented higher amount of nonanoic and hexanoic acids detected by TD-GC-MS in Plastunion samples compared to the other formulated PVC samples (Figure 2).

It is to point out that DINP degradation, as well as phthalic acid formation, is slower with the increase of initial additives concentration in the PVC formulation underlining a potential 
synergistic effect in systems containing both heat stabilizer, plasticizer and other additives as mentioned previously in literature (Szymański and Śmietańska, 1979).

From the results, mechanistic pathways are proposed in Schemes 1 and 2 to explain the formation of radiolytic degradation byproducts of formulated PVC implying DINP plasticizer and other additives like stearate derivative.



Scheme 1: Radiolytic degradation of DINP in formulated PVC

The radiolytic degradation of DINP occurs first by the hydrogen abstraction on the carbon in $\alpha$-position of the ester function leading to the formation of a peroxy radical in the presence of oxygen. The latter can abstract a hydrogen atom from the alkyl chain of another PVC to form a hydroperoxide derivative, itself leading to the formation of an alkoxy radical by the homolytic cleavage of the $\mathrm{O}-\mathrm{OH}$ bond. From this radical, the homolytic $\beta$-cleavage reaction induces the scission of the $\mathrm{C}-\mathrm{O}$ bond and the formation of nonanal and nonyl phthalic acid which has been detected (Table 2). Then, the further oxidation of the aldehyde in the presence of oxygen leads to nonanoic acid and the additional degradation of nonyl phthalic acid generates phthalic acid and 1-nonanol, the main degradation products identified into irradiated samples. These proposed formation pathways are in agreement with the fact that these two products appear to 
be primary ones from their curves. The presence of other C9 alcohol isomers in irradiated samples (Table 1) can be explained by the initial standard composition of DINP used for the PVC formulation, which contains several isomers with branched C9 alkyl chains (nonyl and methyl octyl).

However, the disappearance of DINP probably results from other reaction pathways than direct radiolysis considering the high radiolytic yields calculated from the relationship given in SI (Equation 1). The yield values, between 3.4 to 6.8 molecules/100 eV depending on the PVC formulated sample, confirm that indirect effects of the ionizing radiation are probably involved in DINP transformation. These effects could be attributed to hydrogen atom abstraction on DINP by PVC radicals (mainly peroxyl derivatives) formed under gamma radiation rather than the classical propagation by autooxidation.
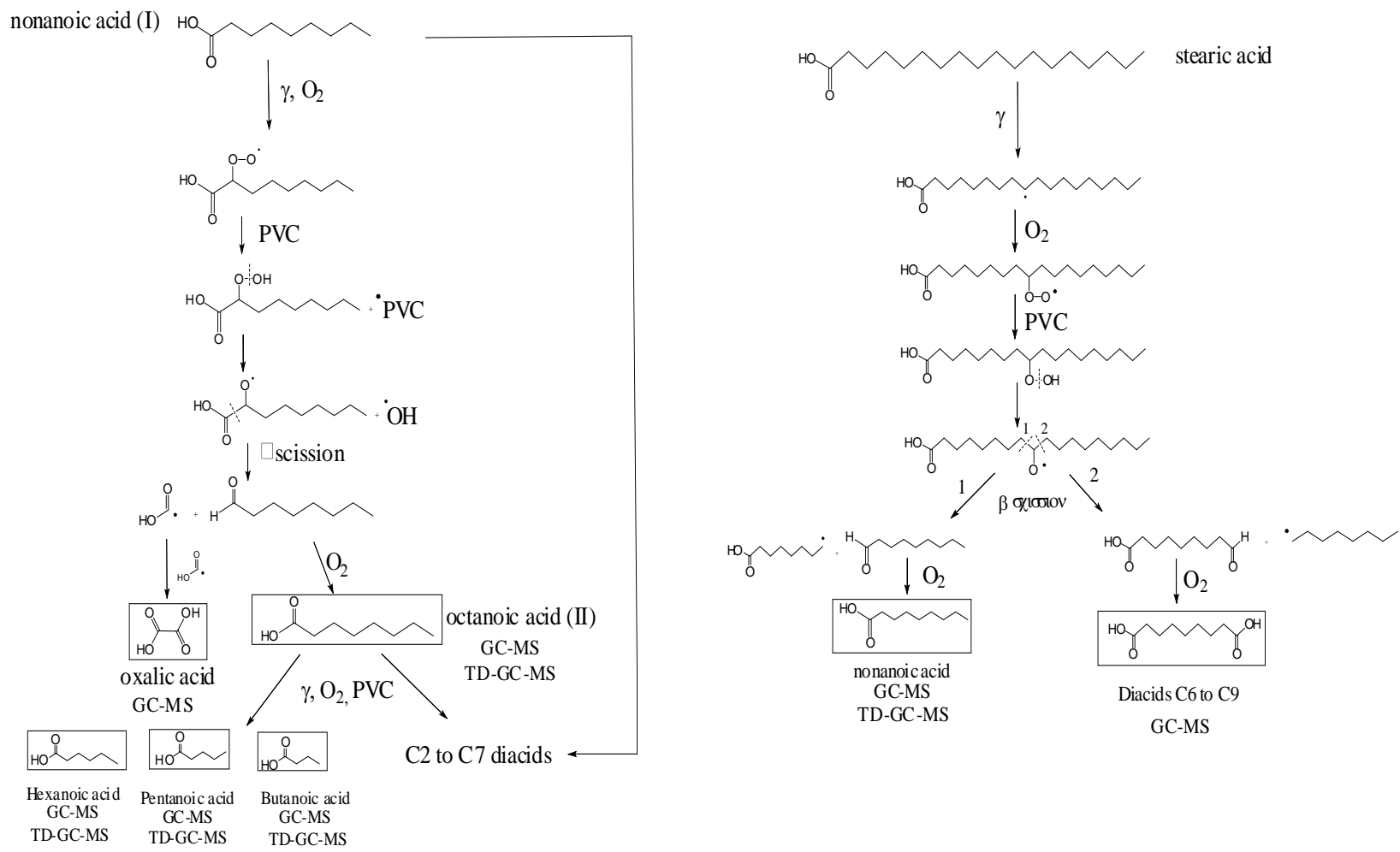

Scheme 2: Radiolytic degradation of nonanoic and stearic acid in PVC formulated samples

As described in Scheme 2, the degradation of nonanoic acid occurs first similarly, by the hydrogen abstraction on the carbon in $\alpha$-position of the carboxylic function leading to the formation of a peroxy radical in the presence of oxygen. After hydrogen abstraction, the hydroperoxyl function is cleaved leading to the alkoxy radical. The subsequent $\beta$-scission reaction leads to the formation on one hand of octanal and octanoic acid from the oxidation of 
the aldehyde and on the other hand of oxalic acid by radical combination of acetic acid radicals. The cleavage of the alkyl chain in different positions may induce the formation of other carboxylic acids (butanoic, pentanoic and hexanoic acids) and dicarboxylic acids from $\mathrm{C} 2$ to C8. Pentanoic and butanoic acids can be also produced from C6 to C8 carboxylic acids by the same mechanisms and could then accumulate in the matrix in agreement with their concentration evolution as a function of $\gamma$-dose

For the long chain dicarboxylic acids (C6 to C9), an additional source may explain their presence into Plastunion irradiated samples. It is proposed that they originate from the radiooxidation of stearic acid used as lubricant, following the same mechanistic pathways as presented in Scheme 2. Depending on whether the $\beta$ scission takes place in (1) or (2), a carboxylic acid or a C6 to C9 diacid will be formed respectively. This hypothesis is supported by the work of Lebeau et al. who detected the formation of $\mathrm{C} 7$ to $\mathrm{C} 11$ carboxylic acids by radiooxidation of magnesium stearate and dicarboxylic acids by $\beta$ scission. It is specified that the latter are formed only for a dose of 1 MGy (Lebeau et al., 2015). In addition, in a more recent study, the same types of by-products were identified by GC-MS during the radiooxidation of calcium stearate (Lebeau et al., 2017).

\section{Conclusion}

The most exhaustive identification of volatile and non-volatile degradation products resulting from the radiooxidation of PVC was conducted on pristine and formulated samples using complementary techniques. It was shown that formulated PVC emits larger amounts and a wider variety of radiooxidation byproducts compared to PVC resin. As previously mentioned in literature, additives delay the formation of PVC matrix byproducts such as $\mathrm{HCl}$ and $\mathrm{H}_{2}$ but also some carboxylic acids and furthermore promote the production of other organic compounds. It was proved that DINP is a major source of byproducts such as phthalic derivatives, alcohols and mono carboxylic acids from $\mathrm{C} 4$ to $\mathrm{C} 9$ and dicarboxylic acids from $\mathrm{C} 2$ to $\mathrm{C} 8$. Other additives are also suspected to contribute. In our case, dicarboxylic acids from C6 to C9 are also generated from the radiooxidation of stearic acid used as lubricant in the commercial PVC. Degradation mechanisms of DINP, nonanoic acid and stearic acid are proposed and allow to explain the formation of most of the detected byproducts during the radiolysis of formulated PVC. 


\section{Acknowledgement:}

ANDRA is thanked for its financial support. Sophie Rouif from IONISOS is acknowledged for her helpful collaboration during irradiations. We show our gratitude to KemOne for having provided us the pure resin and the formulations 1 and 2 . 


\section{References:}

Andra, 2018. National Inventory of radioactive materials and waste, p.14.

Boughattas, I., 2014. Etude de la dégradation thermique du PVC: Effet couplé de l'irradiation et de la température.

Boughattas, I., Pellizzi, E., Ferry, M., Dauvois, V., Lamouroux, C., Dannoux-Papin, A., Leoni, E., Balanzat, E., Esnouf, S., 2016. Thermal degradation of $\gamma$-irradiated PVC: IIIsothermal experiments. Polym. Degrad. Stab. 126, 209-218. https://doi.org/10.1016/j.polymdegradstab.2015.05.010

Colombani, J., 2007. Etude de la radiolyse gamma du polychlorure de vinyl. Application à l'étude de la dégradation par irradiation et par lixiviation du PVC industriel (Thèse).

Colombani, J., Labed, V., Joussot-Dubien, C., Périchaud, A., Raffi, J., Kister, J., Rossi, C., 2007. High doses gamma radiolysis of PVC: Mechanisms of degradation. Nucl. Instrum. Methods Phys. Res. Sect. B Beam Interact. Mater. At. 265, 238-244. https://doi.org/10.1016/j.nimb.2007.08.053

Decker, C., 1976. Oxidative degradation of poly(vinyl chloride). J. Appl. Polym. Sci. 20, 3321-3336. https://doi.org/10.1002/app.1976.070201213

Gaylord, N.G., Adler, G., 1963. Radiation chemistry of polymeric systems high polymers, A. Chapiro, ed., interscience, New York, 1962, xvi + 712 pp. \$21.00. J. Polym. Sci. A 1, 2237-2237. https://doi.org/10.1002/pol.1963.100010646

Hegazy, E.-S.A., Seguchi, T., Machi, S., 1981. Radiation-induced oxidative degradation of poly(vinyl chloride). J. Appl. Polym. Sci. 26, 2947-2957. https://doi.org/10.1002/app.1981.070260911

Hutzler, B.W., Machado, L.D.B., Lugão, A.B., Villavicencio, Anna.-L.C.H., 2000. Properties of irradiated PVC plasticized with non-endocrine disruptor. Radiat. Phys. Chem. 57, 381-384. https://doi.org/10.1016/S0969-806X(99)00472-7

Ito, R., Miura, N., Ushiro, M., Kawaguchi, M., Nakamura, H., Iguchi, H., Ogino, J., Oishi, M., Wakui, N., Iwasaki, Y., Saito, K., Nakazawa, H., 2009. Effect of gamma-ray irradiation on degradation of di(2-ethylhexyl)phthalate in polyvinyl chloride sheet. Int. J. Pharm. 376, 213-218. https://doi.org/10.1016/j.ijpharm.2009.04.019

Kresta, J.E. (Ed.), 1984. Polymer Additives. Springer US, Boston, MA. https://doi.org/10.1007/978-1-4613-2797-4

Krylova, S.V., Ovckinnikov, Y.V., Kulikova, A.Y., Pavlinov, L.I., Litvinov, N.I., LYuTovA, T.M., 1979. EFFECT OF PLASTICIZERS ON THE BEHAVIOUR OF POLYVINYL CHLORIDE IN V-IRRADIATION 9.

Lebeau, D., Beuvier, L., Cornaton, M., Miserque, F., Tabarant, M., Esnouf, S., Ferry, M., 2015. Aging of magnesium stearate under high doses gamma irradiation and oxidative conditions. J. Nucl. Mater. 460, 130-138. https://doi.org/10.1016/j.jnucmat.2015.02.016

Lebeau, D., Esnouf, S., Gracia, J., Audubert, F., Ferry, M., 2017. New generation of nuclear fuels: Stability of different stearates under high doses gamma irradiation in the manufacturing process. J. Nucl. Mater. 490, 288-298. https://doi.org/10.1016/j.jnucmat.2017.04.029

Lerke, I., Szymański, W., 1983. Stabilization of gamma-irradiated poly(vinyl chloride) by epoxy compounds. II. Production of hydroperoxides in gamma-irradiated PVCstabilizer mixtures. J. Appl. Polym. Sci. 28, 513-518. https://doi.org/10.1002/app.1983.070280207

Mendizabal, E., Cruz, L., Jasso, C.F., Burillo, G., Dakin, V.I., 1996. Radiation crosslinking of highly plasticized PVC. Radiat. Phys. Chem. 47, 305-309.

https://doi.org/10.1016/0969-806X(94)00183-K 
Miller, A.A., 1959. Radiation Chemistry of Polyvinyl Chloride. J. Phys. Chem. 63, 17551759. https://doi.org/10.1021/j150580a045

Salovey, R., Luongo, J.P., 1970. Radiolysis of poly(vinyl chloride). J. Polym. Sci. [A1] 8, 209-214. https://doi.org/10.1002/pol.1970.150080119

Schiller, M., 2015. PVC Additives: Performance, Chemistry, Developments, and Sustainability. Carl Hanser Verlag GmbH \& Co. KG, München. https://doi.org/10.3139/9781569905449

Štěpek, J., Daoust, H., 2012. Additives for plastics, chapter 1, p.7.

Szymański, W., Śmietańska, G., 1979. Synergistic effect in gamma-irradiated poly(vinyl chloride) hard foils stabilized by plasticizer-stabilizer systems. J. Appl. Polym. Sci. 23, 791-795. https://doi.org/10.1002/app.1979.070230314

Zahran, A.H., Hegazy, Ezz Eldin, F.M., 1985. Radiation effects on poly (vinyl chloride)—I. gas evolution and physical properties of rigid PVC films. Radiat. Phys. Chem. 1977 26, 25-32. https://doi.org/10.1016/0146-5724(85)90028-7 


\section{SUPPORTING INFORMATIONS}

Additives as a major source of radiolytic organic byproducts of polyvinyl chloride (PVC)

Mathilde Chantreux ${ }^{1,2}$, Denise Ricard ${ }^{2}$, Laurence Asia ${ }^{1}$, Stéphanie Rossignol ${ }^{1}$ and Pascal Wong-Wah-Chung ${ }^{1 *}$

1 Aix Marseille Univ, CNRS, LCE, Marseille, France

2 ANDRA, 1/7 rue Jean Monnet, Châtenay-Malabry, France 
Table 1S: Target doses, integrated minimum and maximum doses and associated mean dose rates $(\mathrm{d})$ of gamma radiations exposure. ${ }^{1}$ Carried out by IONISOS society.

\begin{tabular}{|c|c|c|c|c|}
\hline $\begin{array}{c}\text { Target dose } \\
(\mathrm{kGy})\end{array}$ & $\begin{array}{c}\text { Integrated } \\
\text { minimum dose } \\
(\mathrm{kGy})\end{array}$ & $\begin{array}{c}\text { Integrated } \\
\text { maximum dose } \\
(\mathrm{kGy})\end{array}$ & $\begin{array}{c}\text { Mean dose } \\
(\mathrm{kGy})\end{array}$ & $\begin{array}{c}\text { Mean Dose Rate } \\
\left(\mathrm{kGy} \cdot \mathrm{h}^{-1}\right)\end{array}$ \\
\hline $\mathbf{5 0 0}^{\mathbf{1}}$ & 460 & 528 & 494 & 0.96 \\
\hline $\mathbf{1 0 0 0}^{\mathbf{1}}$ & 1007.4 & 1148.3 & 1077.85 & 0.91 \\
\hline $\mathbf{2 0 0 0}^{\mathbf{1}}$ & 2074.99 & 2239.43 & 2157.21 & 1.68 \\
\hline
\end{tabular}

Figure 1S: Calibration curve obtained for toluene by TD-GC-MS

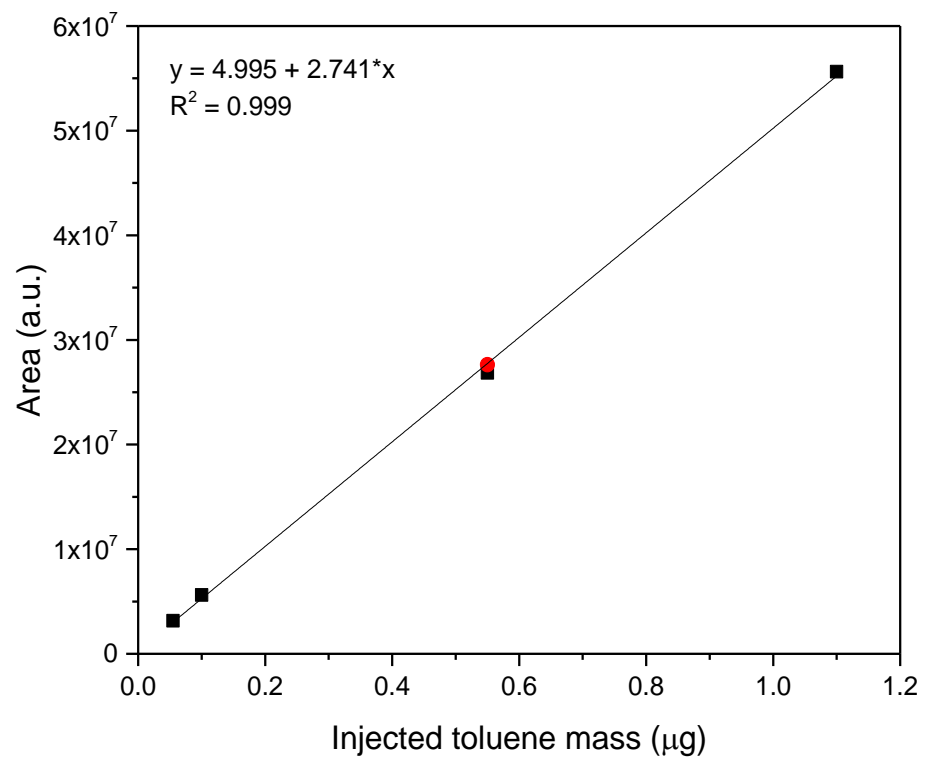


Figure 2S: TIC chromatograms of PVC samples irradiated at 0.5 MGy by TD-GC-MS: (black) resin, (green) Plastunion



Equations 1S: Calculated extraction yield of radiooxidative products

$$
\text { Calculated extraction yield of radiooxidative products }=\frac{A r e a_{r p}^{C=i}}{\sum_{\mathrm{C}=1}^{\mathrm{C}=3} A_{r e}^{\mathrm{C}} \mathrm{a}_{\mathrm{rp}}^{\mathrm{C}=\mathrm{i}}}
$$

With c, number of analysis cycle and $\mathrm{Area}_{\mathrm{rp}}^{\mathrm{c}=\mathrm{i}}$, area of radiooxidative products detected during the cycle $\mathrm{i}(\mathrm{i}=1,2$ or 3 ) with:

$$
\text { Area }_{\mathrm{rp}}^{\mathrm{C}=\mathrm{i}}=\text { Total aera }{ }^{\mathrm{C}=\mathrm{i}}-\text { Area }_{\mathrm{tp}}^{\mathrm{C}=\mathrm{i}}
$$

With Area $_{\mathrm{tp}}^{\mathrm{c}=\mathrm{i}}$, area of thermooxidative products detected during the cycle $\mathrm{i}(\mathrm{i}=1,2$ or 3 ) and Total aera ${ }^{\mathrm{c}=\mathrm{i}}$, total area of COVs measured for the cycle $\mathrm{i}(\mathrm{i}=1,2$ or 3 )

Table 2S: Fractions of desorbed radiooxidative products in percentage after each TD-GC-MS cycle as a function of PVC sample and cumulative gamma radiations dose: first cycle $(\mathrm{C} 1)$, second cycle (C2) and third cycle (C3).

\begin{tabular}{|c|c|c|c|c|c|c|c|c|c|c|c|c|}
\hline Cumulative dose (MGy) & \multicolumn{3}{|c|}{ resin } & \multicolumn{3}{c|}{ F1 } & \multicolumn{3}{c|}{ F2 } & \multicolumn{3}{c|}{ Plastunion } \\
\hline & C1 & C2 & C3 & C1 & C2 & C3 & C1 & C2 & C3 & C1 & C2 & C3 \\
\hline $\mathbf{0 . 5}$ & 100 & 0 & 0 & 88.7 & 10.6 & 0.7 & 87.3 & 9.8 & 2.9 & 89.3 & 9.3 & 1.4 \\
\hline $\mathbf{1}$ & 99.5 & 0.5 & 0 & 86.5 & 12.5 & 1 & 87.5 & 8.8 & 3.7 & 88.0 & 8.6 & 3.4 \\
\hline $\mathbf{2}$ & 97.9 & 1.7 & 0.4 & 94.7 & 5.3 & 0 & 90.6 & 7.6 & 1.8 & 83.8 & 14.6 & 1.6 \\
\hline
\end{tabular}



Figure 3S: $\mathrm{VOC}_{\text {tot }}$ concentration evolution as a function of irradiation dose (in toluene equivalent)



Figure 4S: Area of $\mathrm{HCl}$ and $\mathrm{CO}_{2}$ as a function of $\gamma$-dose by TD-GC-MS: (black) resin, (red) F1, (blue) F2, (green) Plastunion.

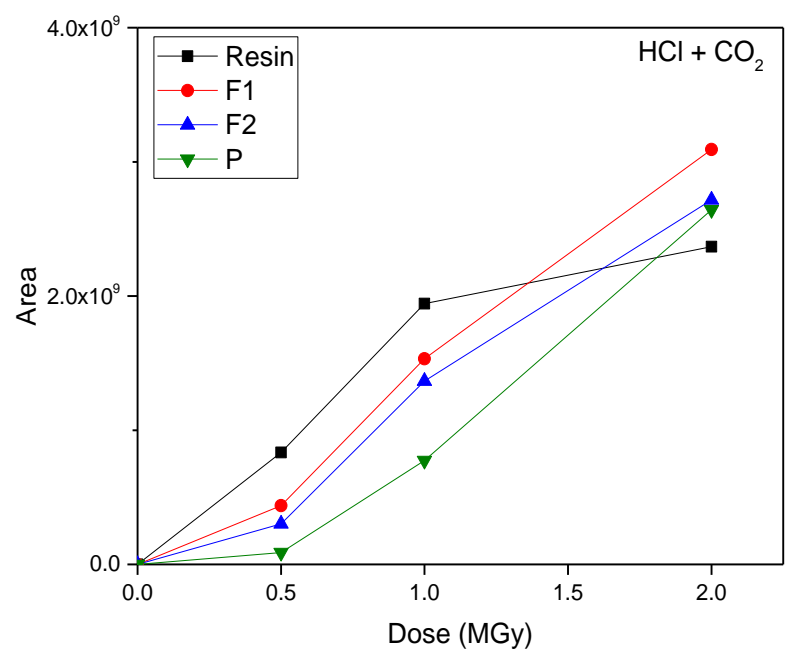


Figure 5S: Concentration evolution of 1-nonanol (A) and 6 methyl, 1-octanol (B) as a function of the $\gamma$-dose in formulated PVC samples determined by TD-GC-MS: (red) F1, (blue) F2 and (green) Plastunion.


\section{Equation 1: radiolytic yield formula}

$\mathrm{G}_{\text {DINP }}=\left(\frac{1}{d(t) * m} * \frac{d n}{d t}\right)$

With: $d(t)$ : dose rate under $\gamma$ radiation at time $t\left(G y . h^{-1}\right)$

$\mathrm{m}$ : PVC sample mass exposed to $\gamma$ radiation $(\mathrm{kg})$

$\frac{d n}{d t}$ : DINP degradation rate at time $\mathrm{t}$ under $\gamma$ radiation $\left(\mathrm{mol}^{-1} \mathrm{~h}^{-1}\right)$

The SI unit is mol. $\mathrm{J}^{-1}$, but conventionally it is expressed in molecules $/ 100 \mathrm{eV}$ in the literature:

$\operatorname{GDINP}($ molecules $/ 100 \mathrm{eV})=0.963 .10^{7} \times \mathrm{G}\left(\mathrm{mol} . \mathrm{J}^{-1}\right)$ 